\title{
Too much of a good thing: High T cell count can kill newborns
}

Angelina Bustos ${ }^{1}$, Lai Xu1 ${ }^{1}$, Garett Dunsmore ${ }^{2}$, Shokrollah Elahi ${ }^{1,2}$

${ }^{1}$ School of Dentistry, University of Alberta

${ }^{2}$ Department of medical microbiology and Immunology, University of Alberta

\begin{abstract}
Neonates have a weakened immune system that could be due to low exposure to pathogens resulting in low adaptive immunity and/or purposeful immune suppression to protect the weak neonate from a robust immune response. The purpose of this project is to find preliminary data to further investigate why the immune system of neonates are weaker, and to possibly improve neonatal immunity while protecting against a powerful immune response in the future. Using processed mice spleen cells that were stained for CD4 and CD8 to be subjected to flow cytometry, an increase in the percent of helper CD4 and killer CD8 T cells were observed as the mice aged. This indicates that neonates do have a weaker immune system. Between healthy mice and mice infected with either Bordetella pertussis or Listeria, a decrease in the percent of CD4 and CD8 T cells were found, which could be because not enough time had passed for an adaptive immune response.
\end{abstract}

Key words:

mouse, BALB/c, T cell, neonate, baby, immune system, adult, CD4, CD8

Cite as: Bustos A., Xu L., Dunsmore G., and Elahi S. 2019. Too much of a good thing: High T cell count can kill newborns. Alberta Academic Review, Vol 2 (2) 15-16, WISEST Special Issue (non peer-reviewed), DOI 10.29173/aar53. 


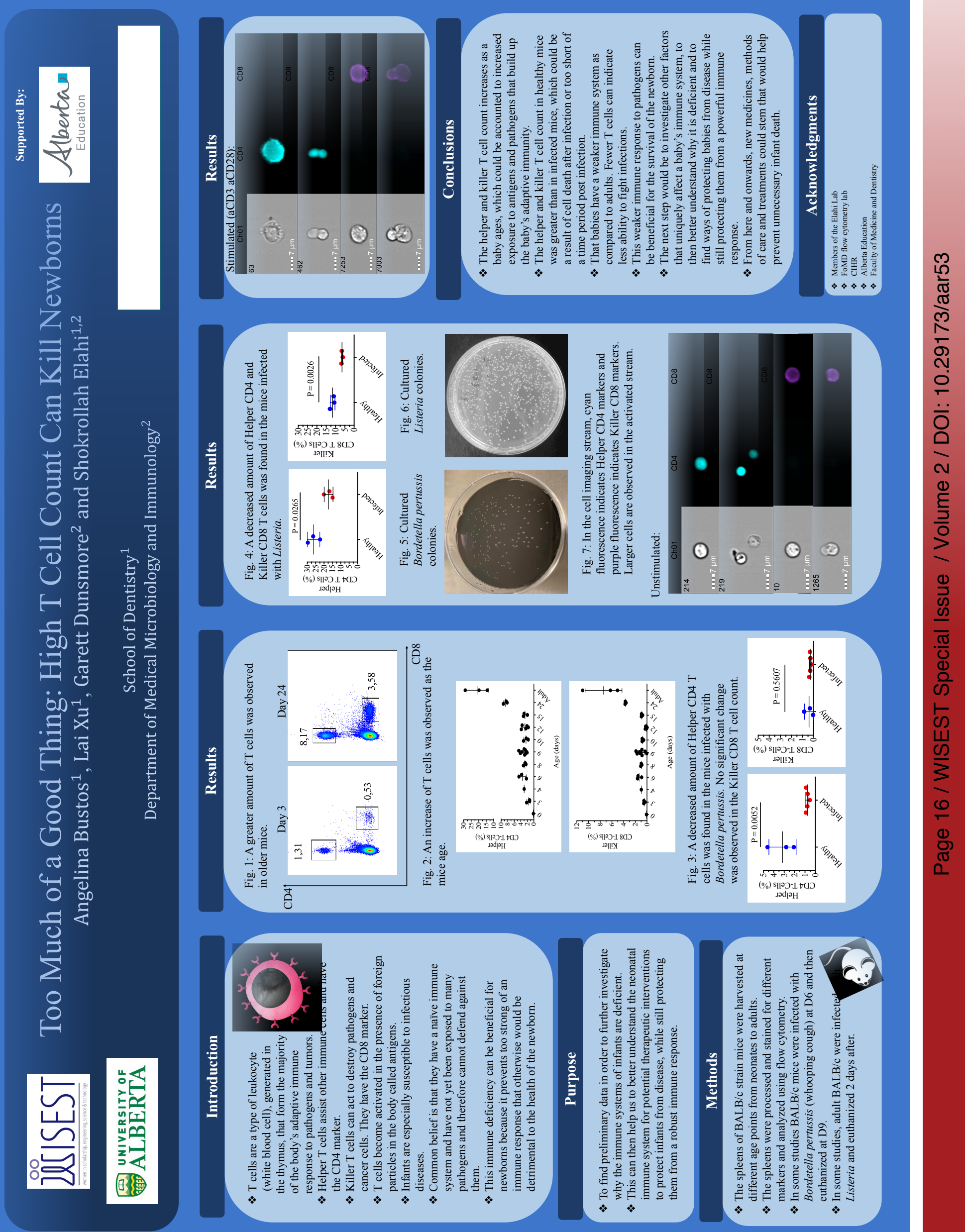

